\title{
Association between Lipoprotein (a) Level with Traditional Risk Factor in Acute Myocardial Infarction Patient
}

\author{
Yose Ramda Ilhami ${ }^{1}$, Rita Hamdani ${ }^{2}$ \\ \{yose_milanisti@yahoo.co.id ${ }^{1}$ \} \\ Medical Faculty, Universitas Andalas, Padang, Indonesia
}

\begin{abstract}
Lipoprotein (a) has a role in atherosclerosis process through prothrombotic effect, anti-fibrinolytic and accelerated atherogenesis. Traditional risk factor plays an important role as an independent risk factor of cardiovascular disease: Association between Lp(a) level with a traditional risk factor and lipid profiles still not giving consistent result yet, so it is needed to research the association between traditional risk factor with $\mathrm{Lp}$ (a) levels. Patient with acute myocardial infarction that was hospitalized in Cardiac Comprehensive Care Installation at M. Djamil Hospital was included in the research. Clinical characteristic and laboratorium were collected, and then statistical analysis was done to see the association and correlation with $\mathrm{Lp}(\mathrm{a})$ level with the cardiovascular risk factor. There were 32 patients with acute myocardial infarction included in the research. Most of the patients were male, had risk factors of hypertension, smoker, and dyslipidemia, had Lp(a) level within normal limit. There were differences between $L p(a)$ level in patients with and without hypertension, while for another cardiovascular risk factors there were no significant differences. Correlation between $\mathrm{Lp}$ (a) level and lipid profiles, there was no significant correlation. There was the difference between $\mathrm{Lp}(\mathrm{a})$ level in a patient with and without hypertension, while there was no significant correlation between Lp(a) with lipid profiles.
\end{abstract}

Keywords: Lipoprotein(A), Traditional Risk Factor, Acute Myocardial Infarction, Lipid Profile.

\section{Introduction}

Lipoprotein (a) is an LDL-like particle that has certain antigens in lipoprotein particles socalled Lp (a). Lipoprotein (a) has apolipoprotein B100 particles and binds to a glycoprotein molecule called apolipoprotein (a) [apo (a)][1]. Lipoprotein (a) contributes to the occurrence of atherosclerosis and atherothrombosis and is associated with the incidence of myocardial infarction [2],[3]. Research in humans and animals shows that Lp (a) can enter the intima layer of the arteries so that it can play a role in the development of atherosclerosis. Lipoprotein (a) can increase the risk of cardiovascular disease through prothrombotic and anti-fibrinolytic effects and acceleration of atherogenesis [4],[5]. However, whether Lp (a) levels can be an independent risk factor of cardiovascular disease or still depends on other cardiovascular risk factors remains controversial.

Traditional risk factors such as diabetes, smoking, hypertension, and dyslipidemia have been shown to act as independent risk factors for cardiovascular disease and therapy for 
traditional risk factors has been shown to reduce cardiovascular events [6],[7]. Several studies have found that non-traditional risk factors such as $\mathrm{Lp}$ (a) and inflammatory biomarkers can be the second-line goal of therapy, after optimal therapy for traditional risk factors [8]. LDL cholesterol levels are significantly associated with elevated levels of Lp (a), while for other risk factors there is no significant association [9]. Association between Lp (a) and lipid profiles specifically both total cholesterol, LDL cholesterol, HDL cholesterol, and triglycerides still provide inconsistent results. Therefore, it is necessary to research to assess the relationship between traditional risk factors for myocardial infarction with levels of Lp (a).

\section{Material and Methods}

We included patients with acute myocardial infarction with either ST elevation (STEMI) or without ST elevation (NSTEMI) who were treated at the Instalasi Pusat Jantung Terpadu at RS Dr. M. Djamil Padang from September to November 2016. Patients with a history of acute myocardial infarction were previously excluded from this study. Written consent to participate in this study was taken from all patients. This study had received ethical approval from the research ethics committee of the Faculty of Medicine, Andalas University.

Information regarding age, sex, hypertension, diabetes mellitus, cigarette use, and dyslipidemia were collected. Hypertension was defined if there was a history of previous hypertension or previous hypertension therapy or if systolic blood pressure was $\geq 140 \mathrm{mmHg}$ or diastolic blood pressure was $\geq 90 \mathrm{mmHg}$. Diabetes mellitus (DM) was defined when there was the previous history of DM or in DM therapy or the presence of fasting blood sugar levels $\geq 126$ $\mathrm{mg} / \mathrm{dL}$ or blood sugar 2 hours post-glucose tolerance test $\geq 200 \mathrm{mg} / \mathrm{dL}$ or the presence of blood sugar levels $\geq 200 \mathrm{mg} / \mathrm{dL}$ with classic symptoms and signs of DM [10]. Cigarettes use were defined when patients still smoke at least one cigarette per day. Dyslipidemia was defined if there was a previous history of dyslipidemia or if $\mathrm{HDL}$ cholesterol was $<40 \mathrm{mg} / \mathrm{dL}$, or triglycerides $>150 \mathrm{mg} / \mathrm{dL}$ or high cholesterol LDL levels following NCEP ATP III [11]. Venous blood samples were taken from patients to measure Lp levels (a) Lipoprotein (a) was measured by enzyme-linked immunosorbent assay (ELISA) using Sandwich-ELISA (Elabscience) method in the Biomedical laboratory of Andalas University.

For statistic analysis, we used an independent t-test to see differences in Lp (a) levels between patients with positive risk factors and negative risk factors, Chi-square tests were used for categorical variables, and correlation tests were used to compare Lp (a) with total cholesterol, LDL cholesterol, HDL cholesterol, and triglycerides. The results of the analysis were said to be significant if the $\mathrm{p}$-value is $<0.05$.

\section{Results}

The clinical characteristics of patients with acute myocardial infarction can be seen in Table 1. The mean age of patients was 56 years, with most patients being male, smoker, had dyslipidemia and hypertension and having $\mathrm{Lp}$ (a) levels in the normal range. 
Table 1. Clinical characteristic acute myocardial infarction patient.

\begin{tabular}{ll}
\hline Parameter & \\
\hline Age (year) & $56,06 \pm 8,12$ \\
Sex (\% male) & $28(87,5)$ \\
Diagnosis (\%) & $17(53,1)$ \\
STEMI & $15(46,9)$ \\
NSTEMI & \\
Risk factor & $19(59,4)$ \\
Hypertension (\%) & $12(37,5)$ \\
Diabetes mellitus (\%) & $22(68,8)$ \\
Smoking (\%) & $19(59,4)$ \\
Dyslipidemia (\%) & $3,36 \pm 0,78$ \\
Lp (a) (mg/dL) & $192,94 \pm 43,48$ \\
Total cholesterol (mg/dL) & $130,53 \pm 39,89$ \\
LDL-cholesterol (mg/dL) & $36,66 \pm 8,01$ \\
HDL-cholesterol (mg/dL) & $136 \pm 73,26$ \\
Triglyceride (mg/dL) &
\end{tabular}

Analysis of differences in Lp levels (a) based on traditional cardiovascular risk factors can be seen in table 2. Patients with hypertension had higher levels of Lp (a) compared to patients without hypertension (3.59 mg / dL vs. $3.02 \mathrm{mg} / \mathrm{dL}, \mathrm{p}<0.05$ ), while for other traditional risk factors there were no statistically significant difference in Lp (a) levels, although there was a lower Lp (a) level in patients with diabetes and patients who smoked.

Table 2. $\mathrm{Lp}(\mathrm{a})$ level difference according to traditional risk factors.

\begin{tabular}{llll}
\hline \multirow{2}{*}{ Risk factor } & \multicolumn{2}{l}{ Lp(a) level $(\mathrm{mg} / \mathrm{dL})$} & \multirow{2}{*}{$\mathrm{P}$} \\
\cline { 2 - 3 } & Risk factor $(+)$ & Risk factor $(-)$ & \\
\hline Hypertension & $3,59 \pm 0,74$ & $3,02 \pm 0,73$ & 0,038 \\
Diabetes mellitus & $3,29 \pm 0,92$ & $3,40 \pm 0,71$ & 0,695 \\
Smoking & $3,28 \pm 0,82$ & $3,54 \pm 0,69$ & 0,389 \\
Dyslipidemia & $3,40 \pm 0,87$ & $3,29 \pm 0,66$ & 0,704 \\
\hline
\end{tabular}

The correlation between levels of Lp (a) and lipid profile can be seen in table 3, where most have a negative correlation with Lp (a) levels, although not statistically significant.

Table 3. $\mathrm{Lp}(\mathrm{a})$ level correlation with lipid profile.

\begin{tabular}{lll}
\hline Parameter & Correlation coefficient & $\mathrm{P}$ \\
\hline Total cholesterol & $-0,239$ & 0,187 \\
LDL cholesterol & $-0,290$ & 0,107 \\
HDL cholesterol & $-0,054$ & 0,767 \\
Triglyceride & 0,002 & 0,991 \\
\hline
\end{tabular}




\section{Discussion}

In this study, we found that most patients were smokers, had hypertension and dyslipidemia, while diabetes mellitus were had by about $37.5 \%$ of patients. Research by Sadeghi et al. in patients with premature coronary artery disease found that the dominant risk factor was dyslipidemia $(77.6 \%)$, followed by smoking $(46.4 \%)$ and hypertension $(35.2 \%){ }^{8}$ In other studies with 542,008 patients with myocardial infarction, the dominant risk factors were hypertension $(52.3 \%)$, followed by smoking $(31.3 \%)$, dyslipidemia $(28.0 \%)$ and diabetes mellitus $(22.4 \%)$ In patients with myocardial infarction, most patients have one or more traditional risk factors, where patients with more risk factors have more atherosclerosis progression than patients who have only a few risk factors [12]. Some study found that there was a decrease in the number of factors traditional risk with increasing age. It is due to some things including age itself increases the risk of coronary heart disease independent of other risk factors, and traditional risk factors will increase the incidence of coronary heart disease so that more die at a younger age.

The mean level of $\mathrm{Lp}$ (a) in this study was $3.36 \pm 0.78 \mathrm{mg} / \mathrm{dL}$. The desired Lp (a) plasma level is below $14 \mathrm{mg} / \mathrm{dL}$, while levels of $14-30 \mathrm{mg} / \mathrm{dL}$ are said to be in the range, 31-50 mg / $\mathrm{dL}$ of high risk and $>50 \mathrm{mg} / \mathrm{dL}$ of very high risk [13]. The risk of myocardial infarction increased with increased levels of $\mathrm{Lp}$ (a) where at levels of $\mathrm{Lp}$ (a)>56 mg / dL there was an increased risk of myocardial infarction 1,5 times compared with levels of $\mathrm{Lp}(\mathrm{a})>15 \mathrm{mg} / \mathrm{dL}$, [5] while Debnath et al found that in patients with acute myocardial infarction, Lp (a) levels were higher than controls $(78.2 \pm 5.9 \mathrm{mg} / \mathrm{dL}$ vs. $30.2 \pm 2.5 \mathrm{mg} / \mathrm{dL})$ [14]. High levels of $\mathrm{Lp}$ (a) were usually found in patients with premature coronary heart disease [4].

The effect of $\mathrm{Lp} \mathrm{(a)} \mathrm{on} \mathrm{the} \mathrm{increased} \mathrm{cardiovascular} \mathrm{event} \mathrm{is} \mathrm{through} \mathrm{its} \mathrm{role} \mathrm{in} \mathrm{intimal}$ inflammation, thrombosis and foam cell formation in the atherosclerosis process [4]. Another mechanism is through the anti-fibrinolysis effect of $\mathrm{Lp}(\mathrm{a})$. The effect of fibrinolysis is acquired because the structure of Lp (a) is similar to plasminogen, so Lp (a) will compete with plasminogen on plasminogen receptors, that will result in reduced fibrinolysis and through the effect of $\mathrm{Lp}$ (a) in stimulating secretion of plasminogen activator inhibitor-1 (PAI- 1) which will produce the thrombogenesis process. In addition to the above effects Lp (a) will also carry oxidized phospholipids which are pro-inflammatory and atherogenic that will attract inflammation cell in blood vessel wall so there will be smooth muscle cell proliferation and atherosclerotic plaque [13],[15].

In this study, we found there are significant differences in Lp (a) levels in patients with hypertension (3.59 mg / dL vs. $3.02 \mathrm{mg} / \mathrm{dL}$ with $\mathrm{p}=0.038$ ), while for $\mathrm{Lp}$ (a) relationship with other traditional risk factors, are not significantly different. Sinha et al. found that Lp (a) levels were higher in patients with hypertension. Patients with hypertension and have higher levels of Lp (a) are at greater risk for cardiovascular disease compared with just only have one risk factor[16]. In groups of patients with diabetes higher levels of Lp (a) is obtained in patients with nephropathy than patients without nephropathy $(35,7 \pm 2.2 \mathrm{mg} / \mathrm{dL}$ vs. $24.1 \pm 2.4 \mathrm{mg} / \mathrm{dL}, \mathrm{p}=$ $0.001) .[17]$

The correlation between levels of Lp (a) and lipid profile in this study is a negative correlation that is not statistically significant. The study by Hernandez et al found a positive correlation between Lp (a) with total cholesterol $(r=0.29, p<0.001)$, LDL cholesterol $(r=0.30$, $\mathrm{p}=0.001)$, and apo B $(0.24, \mathrm{p}=0.02)$. The positive correlation between Lp (a) and LDL cholesterol is caused by several things, including the presence of a common catabolism pathway between Lp (a) and LDL. The rate of apo B secretion from the liver which is a good source of 
Lp (a) and LDL cholesterol and the calculation of LDL levels using Friedewald's formula using cholesterol contained in Lp (a) particles.[3]

Hernandez et al. also found an inverse relationship between Lp (a) and triglycerides. This can occur due to the role of plasma triglycerides in the metabolism of Lp (a) and because of the presence of apo (a) in triglyceride-rich particles (TRP) which together with the chylomicron remnant that will be taken quickly by the liver, thus experiencing a faster clearance compared with apo catabolism (a) in LDL cholesterol.[3]

The limitation of this study is that there is no comparison between Lp (a) levels of patients with Lp (a) control levels. Therefore, they cannot answer the increase in Lp (a) levels in patients with acute myocardial infarction, and all patients have Lp (a) levels in the normal range so it cannot assess the effect of Lp (a) on acute myocardial infarction

\section{Conclusion}

There is a higher level of $\mathrm{Lp}(\mathrm{a})$ in the patient with hypertension compared with not hypertension, while for another traditional risk factor there is no significant difference.

\section{References}

[1] Maranhao RC, Carvalho PO, Strunz CC, Pileggi F. Lipoprotein (a): Structure, Pathophysiology and Clinical Implications. Arq Bras Cardiol. 2014; 103(1):76-84

[2] Kampstrup PR, Benn M, Tybjaerg-Hansen A, Nordestgaard BG. Extreme Lipoprotein (a) Levels and Risk of Myocardial Infarction in the General Population. The Copenhagen City Heart Study. Circulation. 2008;117:176-84

[3] Hernandez C, Chacon P, Garcia-Pascual L, Simo R. Differential Influence of LDL Cholesterol and Triglycerides on Lipoprotein(a) Concentrations in Diabetic Patients. Diab Care. 2001;24:350-55

[4] Saeedi R, Frohlich J. Lipoprotein (a), an independent cardiovascular risk marker. Clin Diab and Endocrinology. 2016;2(7)

[5] Nordestgaard BG, Chapman MJ, Ray K, Boren J, Andreotti F, Watts GF et al. Lipoprotein(a) as a cardiovascular risk factor: current status. Eur Heart Jou. 2010;31:2844-53

[6] Chen J, Zhang Y, Liu J, Chen M, Guo Y, Zhu C et al. Role of lipoprotein(a) in predicting the severity of new onset coronary artery disease in type 2 diabetics: A Gensini score evaluation. Diab \& Vasc Dis Res. 2015;12(4):258-64

[7] Khot UN, Khot MB, Bajzer CT, Sapp SK, Ohman EM, Brener SJ et al. Prevalence of conventional risk factors in patients with coronary heart disease. JAMA. 2003;290:898-904

[8] Sadeghi R, Adnani N, Erfanifar A, Gachkar L, Maghsoomi Z. Premature coronary heart disease and traditional risk factors-can we do better. Int Cardivasc Res J. 2013;7(2):46-50

[9] Afshar M, Pilote L, Dufresne L, Engert JC, Thanassoulis G. Lipoprotein(a) interactions with low-density lipoprotein cholesterol and other cardiovascular risk factors in premature acute coronary syndrome (ACS). J Am Heart Assoc. 2016;5:e003012

[10] American Diabetes Association. Standards of medical care in diabetes - 2012 position statement. Diab Care. 2012 Jan;35(suppl 1):S11-63

[11] National Cholesterol Education Program Expert Panel on Detection, Evaluation, and Treatment of High Blood Cholesterol in Adults (Adult Treatment Panel III). 2002.p5 - 11

[12] Canto JC, Kiefe CI, Rogers WJ, Peterson ED, Frederick PD, French Wj et al. Number of coronary heart disease risk factors and mortality in patients with first myocardial infarction. JAMA. 2011;306(19):2120-7 
[13] Khan HA. Lipoprotein(a) as a Biomarker for Risk Stratification of Acute Myocardial Infarction. Ann Clin Exp Metabol. 2016;1(1):1004

[14] Debnath T, Roy S, Majumdar B, Chakraborty A, Pal PS, Mondal MC. Lipoprotein (a) levels in acute myocardial infarction patients admitted in intensive cardiac care unit of Tripura medical college: a clinical study to evaluate lipoprotein(a) as risk factor for AMI and comparison with healthy subjects. Int Jou Pharm Chem Biolog Sci. 2016;6(2);222-6

[15] Tayal D, Goswami B, Koner BD, Mallika V. Role of homocysteine and lipoprotein(a) in atherosclerosis: An update. Biomed Res. 2011;22(4):391-405

[16] Sinha R, Bhushan I. Study of Serum Lipoprotein(a) and Lipid Profile in Patients with Untreated essential hypertension in North Indian population. Jou of Dent and Medic Sci. 2015;14(9):4750

[17] Lakhotia M, Gehlot RS, Jain P, Sharma S, Singh M. Lipoprotein (a) in type 2 diabetic subjects in relation to diabetic microvascular complications. Jou Ind Acad of Clin Med. 2003;4(4):304-7 